\title{
Manufacturing and Testing of Electrical Pneumatic System Trainers at the Laboratory of Politeknik Piksi Ganesha Indonesia
}

\section{Pembuatan dan Pengujian Trainer Sistem Elektro Pneumatik di Laboratorium Politeknik Piksi Ganesha Indonesia}

\author{
Hamid Nasrullah ${ }^{1 *}$, Bahtiar Wilantara ${ }^{1}$, Mohamad Saifudin $^{1}$, Fandi Nugroho ${ }^{1}$
}

\begin{abstract}
The manufacture and testing of the electro pneumatic trainer aims to overcome the limitations of the learning media and determine the effectiveness of the trainer as a learning medium for pneumatic courses. This research uses research and development (R\&D) methods. The data analysis technique used was descriptive qualitative analysis technique. The results of the program and functional input testing show that: (1) The push button test as I/O input works well; (2) The functional test of the trainer when given an average pressure of 79.5 psi produces a pneumatic piston speed output of $0.444 \mathrm{~m} / \mathrm{s}$. Based on the test results, it can be concluded that the making of the Electro Pneumatic Trainer learning media can function properly.
\end{abstract}

Keywords

Pneumatic Electro Trainer, RED, learning media

\begin{abstract}
Abstrak
Pembuatan dan Pengujian trainer elektro pneumatik bertujuan untuk mengatasi keterbatasan media pembelajaran serta mengetahui efektifitas trainer sebagai media pembelajaran pada Mata Kuliah Pneumatik. Penelitian ini menggunakan metode penelitian dan pengembangan (R\&D). Metode analisis data yang digunakan adalah metode analisis deskriptif kualitatif. Hasil pengujian input program dan fungsional menunjukan bahwa: Pertama, Pengujian push button sebagai input I/O bekerja dengan baik; Kedua, Pengujian fungsional trainer ketika diberi tekanan rata rata 79,5 psi menghasilkan output kecepatan piston pneumatik sebesar $0,444 \mathrm{~m} / \mathrm{s}$. Berdasarkan hasil pengujian dapat disimpulkan bahwa pembuatan Trainer Elektro Pneumatik dapat berfungsi dengan baik sesuai prosedur.
\end{abstract}

\section{Kata Kunci}

Trainer Elektro Pneumatik, R\&D, media pembelajaran

${ }^{1}$ Mesin Otomotif Politeknik Piksi Ganesha Indonesia, Indonesia, 54316

*hamidnasrullah9@gmail.com

Submitted : January 06, 2022. Accepted : January 25, 2022. Published : February 25, 2022. 


\section{PENDAHULUAN}

Perguruan tinggi vokasi merupakan sebuah lembaga yang mengutamakan lulusannya sebagai tenaga trampil dibidangnya. Hal ini tentunya harus didukung dengan sarana media pembelajaran yang memadai. Perangkat pembelajaran merupakan sebuah alat untuk menampilkan informasi terkait materi serta dapat dimanfatkan untuk mendorong minat individu dalam membentuk proses pembelajaran [1][2]. Dengan adanya media tersebut diharapkan mahasiswa dalam mempelajari dan memahami dapat tercapai dengan hasil yang baik. Media pembelajaran dibuat sesuai dengan kebutuhan dan perkembangan industri era sekarang yang telah memasuki era Revolusi Industri 4.0 [3]. Dalam hal ini upaya yang dijalankan yaitu melakukan pengembangan media berupa media trainer.

Trainer merupakan sebuah alat bantu bentuk benda nyata yang digunakan sebagai media pembelajaran [4][5]. Dengan adanya trainer tersebut bertujuan untuk membantu kegiatan proses belajar mahasiswa, sehingga nantinya mahasiswa dapat meningkatkan skill kompetensi berupa kemampuan pengetahuan dan keterampilan [6][7]. Pemakaian media trainer tersebut mampu menumbuhkan keterampilan baik praktik yang bersifat teknis ataupun non- teknis seperti pada dunia kerja [5]. Pengembangan media trainer juga didukung langkah pencapaian tujuan pembelajaran bagi pengajar [8].

Proses perumusan ide berawal dari pengamatan langsung sekaligus wawancara kepada kaprodi Program Studi Mesin Otomotif Politeknik Piksi Ganesha Indonesia. Hasil dari wawancara di Laboratorium Mesin Otomotif yaitu belum tersedianya trainer sistem elektro pneumatik sehingga menyulitkan mahasiswa dalam memahami materi maupun praktik.

Sistem elektro pneumatic merupakan system yang mengaplikasikan rangkaian dengan transmisi gaya yang menghasilkan gerakan linier bolak-balik piston dengan menggunakan tekanan udara terkompresi yang ada pada kompressor. Media trainer elektro pneumatik dibuat untuk mengatasi keterbatasan media pembelajaran yang ada di laboratorium Teknik Mesin Otomotif Politeknik Piksi Ganesha Indonesia.

Berdasarkan dari pembahasan diatas maka penulis membuat sebuah rancangan media pembelajaran simulasi trainer sistem elektro pneumatik untuk mengatasi masalah keterbatasan media pembelajaran yang ada di Laboratorium Mesin Otomotif Politeknik Piksi Ganesha Indonesia. Tujuan dari pembuatan trainer ini yaitu [9] (1) Sebagai sarana pembelajaran mahasiswa pada mata kuliah pneumatik dan hidrolik; (2) Sebagai peningkatan kompetensi yang dibutuhkan dalam industry; (3) Mengaplikasikan yang abstrak sehingga dapat menjadi media pembelajaran nyata [10].

\section{METODE PENELITIAN}

\section{Material}

Perlengkapan dan bahan yang digunakan dalam proses pembuatan trainer system elektro pneumatik antara lain [11]: Kompressor, Cylinder Pneumatik, Air Service Unit, solenoid Valve 5/2, Power Supply 24V, Relay, Push Button, Akrilik, Besi Hollow, Kabel, Cat, Capit Buaya, Bor Listrik, Gerinda potong, Kuas, Las Listrik, Spidol, Kacamata Las, Meteran, APD, Tang, Obeng, Mur dan Baut.

\section{Metode}

Penelitian ini menggunakan metode penelitian dan pengembangan (R\&D) [12]. Metode analisis data yang digunakan yaitu metode analisis deskriptif kualitatif. Analisis tersebut digunakan untuk memaparkan hasil pengembangan produk berupa trainer elektro pneumatik dan pengujian fungsional produk. Penelitian ini dirancang dengan mengggunakan model 4D yaitu; Define (pendeskripsian), Design (rancangan), Development (perluasan) serta Dessemination (penyaluran) [13]. Berikut ini diagram alur model pengembangan 4D yang disajikan pada Gambar 1. 


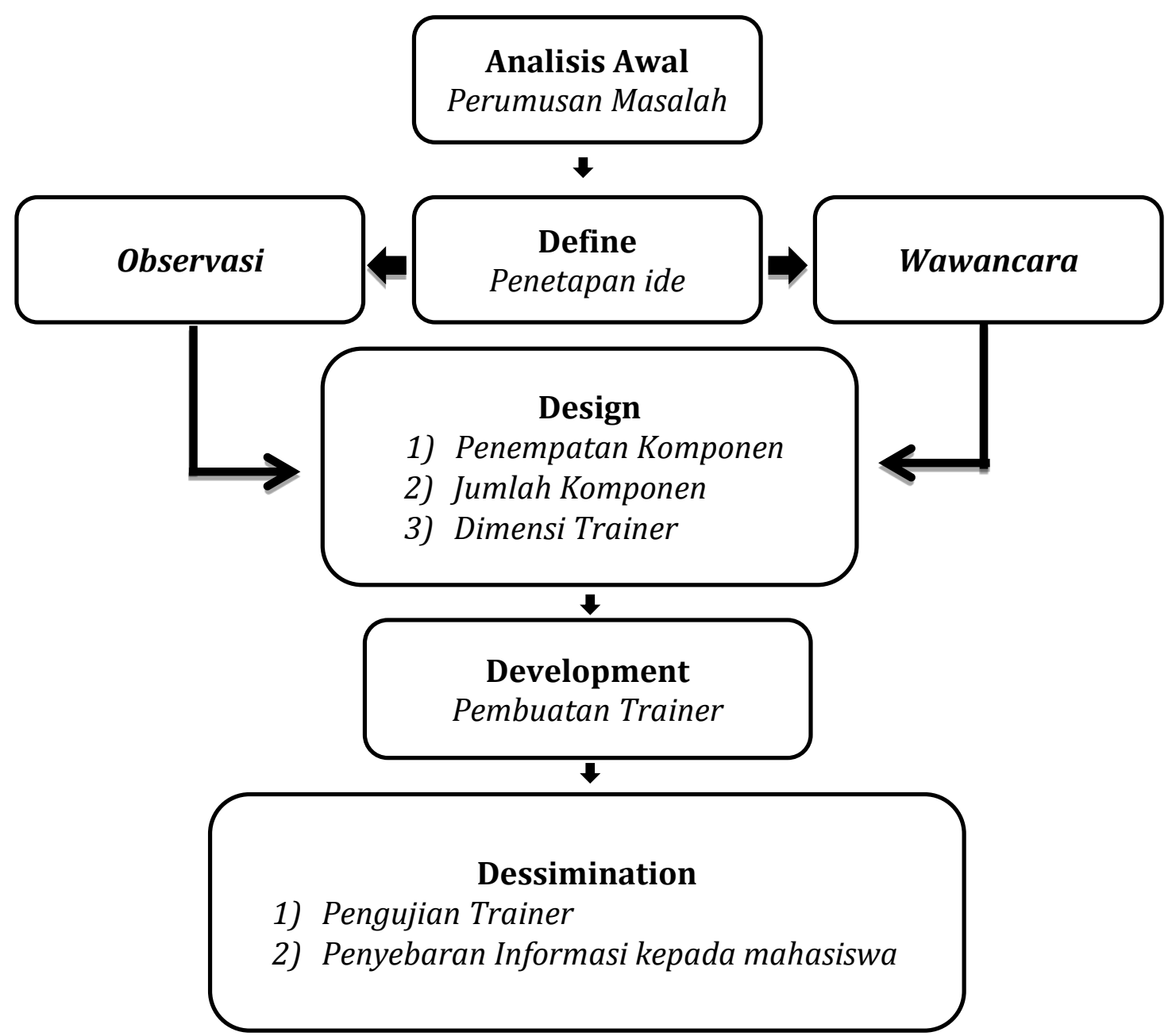

Gambar 1. Prosedur Pengembangan model 4D

Kemudian dalam desain perancangan pembuatan trainer system elektro pneumatik bertujuan untuk menempatkan setiap komponen dan dimensi trainer yang disajikan pada Gambar 2.

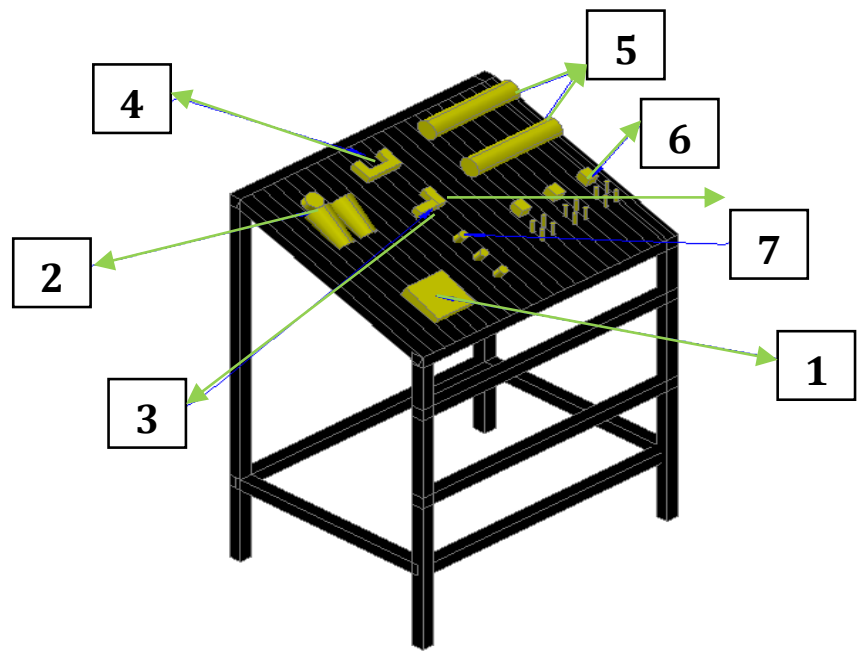

Gambar 2. Desain Awal Trainer Elektro Pneumatik Keterangan: (1) Power Supply; (2)Air Service Unit; (3) Selenoid Valve Single Coil; (4) Selenoid Valve 5/2 Double Coil; (5\&6) Cylinder Pneumatic; (7)Push Buttom 
Spesifikasi Media Trainer merupakan data yang disampaikan untuk memberikan informasi tentang trainer elektro pneumatik. Berikut ini Spesifikasi trainer elektro pneumatik pada Tabel 1.

\section{Tabel 1. Spesifikasi Trainer Elektro Pneumatik}

\begin{tabular}{|l|l|}
\hline Kategori & Spesifikasi \\
\hline Tinggi Tiang Belakang & $100 \mathrm{~cm}$ \\
\hline Tinggi Tiang Depan & $80 \mathrm{~cm}$ \\
\hline Lebar Samping & $50 \mathrm{~cm}$ \\
\hline Lebar Depan & $70 \mathrm{~cm}$ \\
\hline Tekanan Kerja & 9 Psi \\
\hline Tekanan Cylinder & Max 145 Psi $/ 1 \mathrm{Mpa}$ \\
\hline Power Switching & $24 \mathrm{~V} / 5 \mathrm{~A}$ \\
\hline Selenoid Valve & Tipe $5 / 2$ \\
\hline
\end{tabular}

Mekanisme cara kerja dari trainer elektro pneumatik disajikan pada Gambar 3. Sebagai berikut.

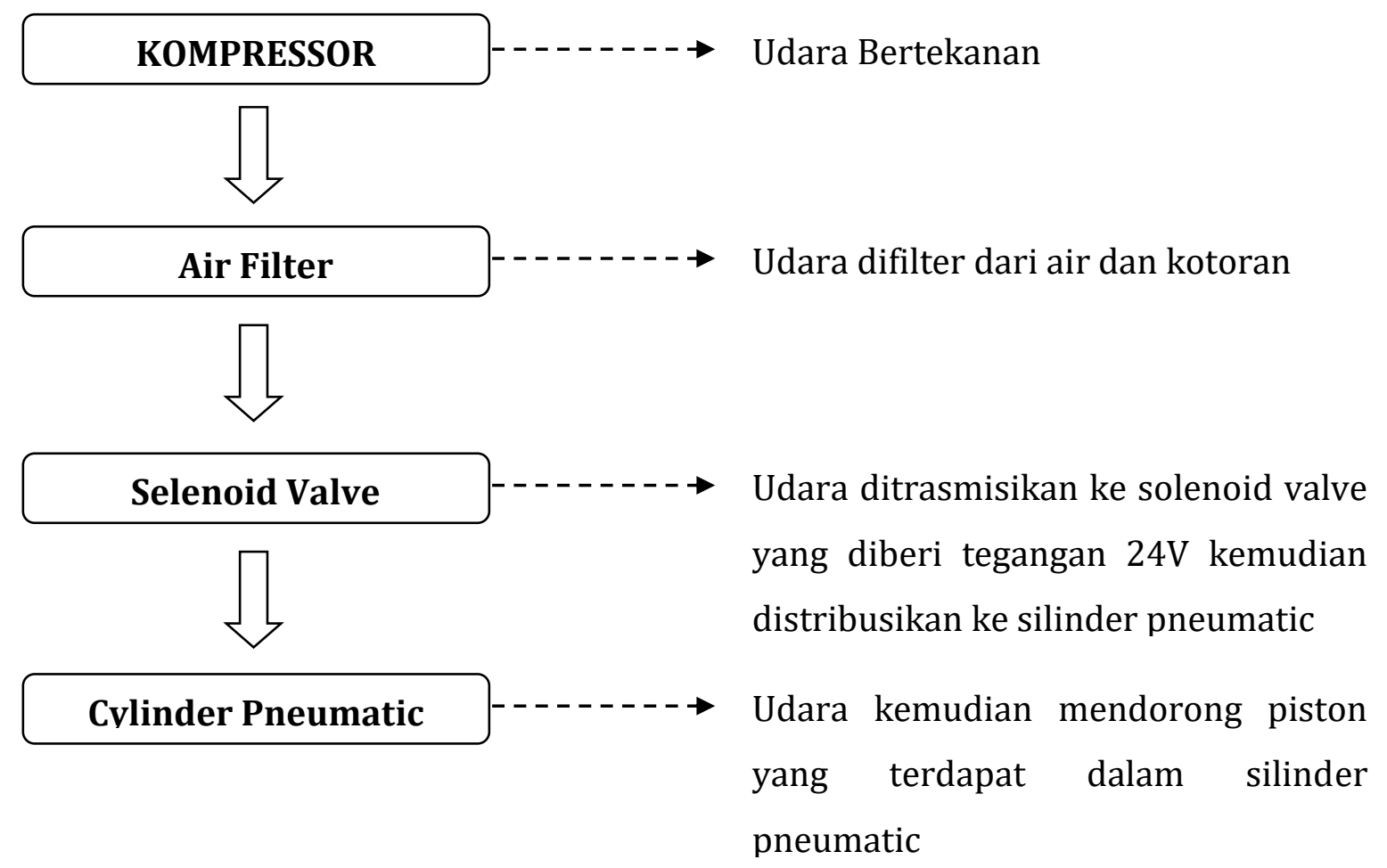

Gambar 3. Diagram Alur Kerja Trainer Pneumatic

Cara kerja aarı traıner eıektro pneumatıc yaıtu bermulaı aarı sumber udara yang dimampatkan pada compressor untuk menyimpan tekanan angin dengan tekanan antara 14 sampai 145 Psi, dari udara bertekanan tersebut kemudian dialirkan menuju ke air filter untuk dilakukan penyaringan dari kemungkinan air dan pelumasan [14]. Setelah melewati air filter, udara bertekanan kemudian menuju ke solenoid valve $5 / 2$ baik single coil maupun double coil. Selenoid valve diberikan sumber tegangan yang berasal dari power switching 24V 5A. Energy listrik dari power switching digunakan untuk menggerakan dua katup output pada solenoid. Ketika katup pertama membuka maka udara akan menuju ke saluran masuk A silinder dan sebaliknya ketika katup kedua membuka udara akan menuju ke saluran B silinder pneumatic. Dari hal tersebut sehingga menghasilkan gerakan linier bolak-balik piston 
dari tekanan udara terkompresi compressor [15][16][17]. Dari mekanisme tersebut maka system pneumatik dapat bekerja dengan baik.

\section{HASIL DAN PEMBAHASAN}

\section{Hasil Produk}

Hasil pembuatan merupakan tahap pengembangan media pembelajaran berupa trainer elektro pneumatik yang sudah dilakukan tahap uji coba disajikan dalam Gambar 4. sebagai berikut.

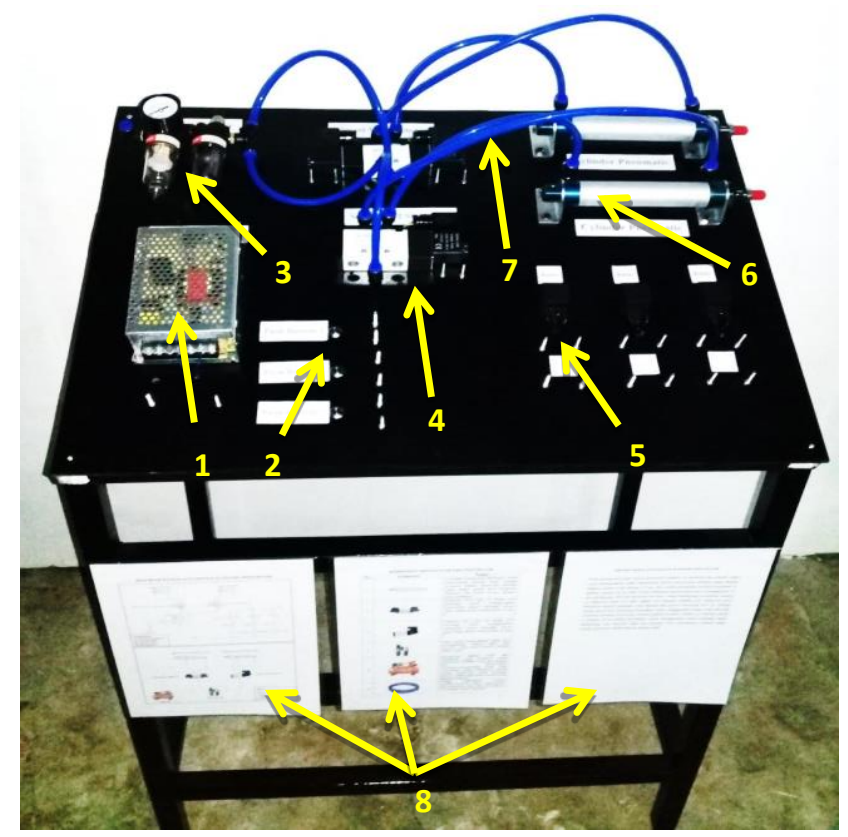

Gambar 4. Hasil Pembuatan Trainer Elektro Pneumatik

Keterangan: (1)Power Supply; (2) Push Buttom; (3) Air Filter

Regulator; (4) Selenoid Valve 5/2; (5) Relay; (6) Cylinder Pneumatik;

(7) Selang; (8) Informasi Trainer Elektro Pneumatik

\section{Pengujian Program Input}

Pengujian trainer elektro pneumatik dilakukan untuk mengetahui dan memastikan bahwa pembuatan semua komponen dapat berfungsi sesuai fungsinya. Pengujian dilakukan dengan menekan tombol push button sebagai input untuk memastikan bahwa rangkaian dapat bekerja dengan normal. Hasil dari pengujian program disajikan pada Tabel 2. berikut.

Tabel 2. Hasil Pengujian Program Input

\begin{tabular}{|c|c|c|c|}
\hline \multirow{2}{*}{ No } & \multirow{2}{*}{ Input I/O } & \multicolumn{2}{|c|}{ Hasil Pengujian } \\
\cline { 3 - 4 } & Push Button 1 & Sebelum ditekan & Sesudah ditekan \\
\hline 1 & Push Button 2 & Close & Open \\
\hline 2 & Push Button 3 & Close & Open \\
\hline 3 & & Open \\
\hline
\end{tabular}

Berdasarkan hasil pengujian di atas ketika push buttom keadaan belum ditekan adalah close atau rangkaian belum bekerja sehingga aliran udara masih tertahan pada solenoid valve, maka ketika ketika push buttom ditekan akan memasukan perintah open untuk mengalirkan aliran udara ke masing-masing silinder penumatik dengan daya yang diperoleh dari power 
supplay 24V. Dari hasil tersebut maka trainer elektro pneumatik dapat berfungsi dengan baik.

\section{Pengujian Fungsional Alat}

Pengujian fungsional alat dilakukan untuk mengetahui komponen elektro pneumatic bekerja sesuai dengan fungsinya. Pengjujian dilakukan dengan memberi tekanan udara antara 14 Psi sampai 145 Psi. Hasil pengujian fungsional disajikan pada Tabel 3.

\section{Tabel 3. Hasil dari Pengujian Tekanan dengan Kecepatan Piston}

\begin{tabular}{|c|c|c|}
\hline Diameter & \multirow{2}{*}{ Pressure (Psi) } & Hasil Pengujian \\
\cline { 3 - 3 } Pitson (mm) & & $0,34 \mathrm{~m} / \mathrm{s}$ \\
\hline 25 & 14 & $0,36 \mathrm{~m} / \mathrm{s}$ \\
\hline 25 & 29 & $0,38 \mathrm{~m} / \mathrm{s}$ \\
\hline 25 & 43 & $0,40 \mathrm{~m} / \mathrm{s}$ \\
\hline 25 & 58 & $0,43 \mathrm{~m} / \mathrm{s}$ \\
\hline 25 & 72 & $0,46 \mathrm{~m} / \mathrm{s}$ \\
\hline 25 & 87 & $0,48 \mathrm{~m} / \mathrm{s}$ \\
\hline 25 & 101 & $0,51 \mathrm{~m} / \mathrm{s}$ \\
\hline 25 & 116 & $0,53 \mathrm{~m} / \mathrm{s}$ \\
\hline 25 & 130 & $0,55 \mathrm{~m} / \mathrm{s}$ \\
\hline 25 & 145 & $\mathbf{0 , 4 4} \mathbf{m} / \mathbf{s}$ \\
\hline
\end{tabular}

Berdasarkan Tabel 3. diatas pengujian dilakukan dengan memberi tekanan bervariasi antara 14 sampai 145 psi maka respon piston silinder akan mengikuti input tekanan yang diberikan. Ketika tekanan tinggi maka kecepatan piston akan lebih cepat, bersamaan dengan itu kecepatan piston akan lambat ketika tekanan yang diberikan kecil. Hasil pengujian fungsional tekanan rata-rata sebesar 79,5 Psi menghasilkan output kecepatan piston 0,44 $\mathrm{m} / \mathrm{s}$. Dari hasil tersebut menandakan bahwa komponen pneumatic dapat bekerja dengan baik sesuai dengan tekanan dari compressor.

\section{Pembahasan}

Gambar 5 merupakan grafik perbandingan hasil pengujian tekanan piston pneumatic dengan output kecepatan piston yang dihasilkan.

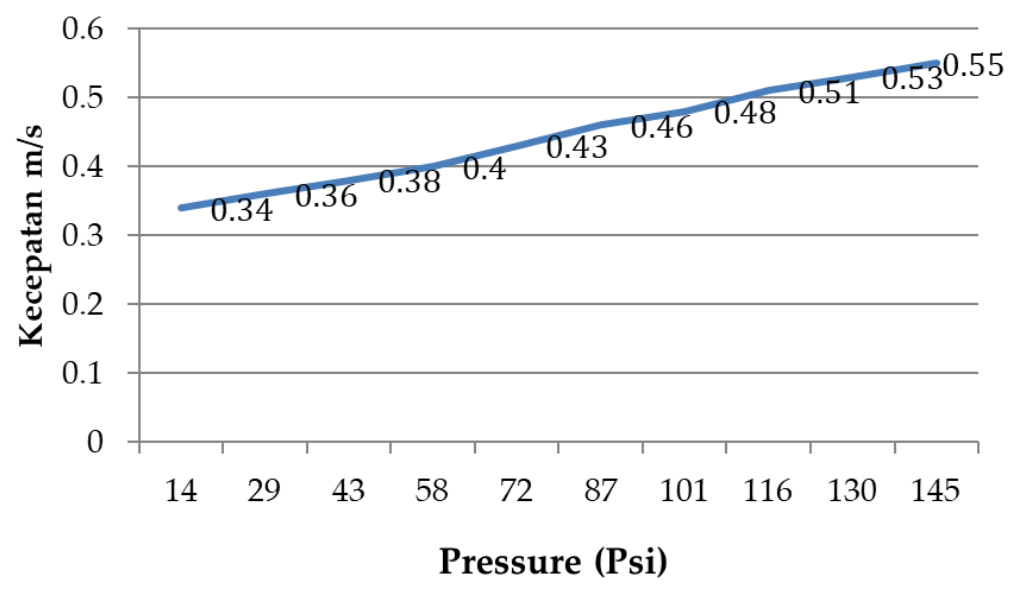

Gambar 5. Grafik Hasil Pengujian 
Berdasarkan Gambar 5, pengujian dilakukan sebanyak 10 kali percobaan dengan pemberian tekanan angina yang berbeda-beda. Pengujian tekanan mulai dari 14 sampai 145 Psi. Ketika piston diberi tekanan 14 Psi menghasilkan kecepatan piston sebesar 0,34 m/s, tekanan 29 Psi menghasilkan keceatan 0,36 m/s, tekanan 43 Psi menghasilkan keceatan 0,38 $\mathrm{m} / \mathrm{s}$, tekanan 58 Psi menghasilkan keceatan 0,40 m/s, tekanan 72 Psi menghasilkan keceatan $0,36 \mathrm{~m} / \mathrm{s}$, tekanan 29 Psi menghasilkan keceatan 0,36 m/s, tekanan 29 Psi menghasilkan keceatan 0,43 m/s, tekanan 87 Psi menghasilkan keceatan 0,46 m/s, tekanan 101 Psi menghasilkan keceatan 0,48 m/s, tekanan 116 Psi menghasilkan keceatan 0,51 m/s, tekanan 130 Psi menghasilkan keceatan 0,53 m/s, tekanan 145 Psi menghasilkan keceatan 0,55 m/s. Dari hasil grafik menunjukan bahwa semakin besar tekanan yang diberikan maka kecepatan piston penumatik akan bertambah cepat sesuai dengan pemberian tekanan anginnya. Berdasarkan pengembangan dan pengujian yang telah dilakukan, sistem trainer elektro pneumatic membutuhkan tegangan supplay $24 \mathrm{~V}$ serta membutuhkan tekanan udara minimum sebesar 9 Psi.

\section{SIMPULAN}

\section{Simpulan}

Berdasarkan hasil pembuatan dan pengujian trainer elektro pneumatik di Laboratorium Prodi Mesin Otomotif Politeknik Piksi Ganesha Indonesia dikembangan menggunakan penelitian dan Pengembangan dengan mengadopsi model 4D yaitu Define, Design, Develop, dan Dissemination. Dari hasil tersebut dapat disimpulkan bahwa trainer elektro pneumatik dapat berfungsi sesuai fungsinya. Hal ini dapat dilihat dari hasil pengujian trainer diberi tekanan 14 sampai 145 psi. Dengan hasil pengujian tersebut maka trainer elektro pneumatik dapat berfungsi sesuai fungsinya serta layak digunakan sebagai media pembelajaran mata kuliah pneumatik.

\section{Saran}

Trainer ini masih sederhana sehingga diharapkan kedepannya dapat menambahkan inovasi lainnya. Dan untuk mendapatkan hasil yang maksimal diharapkan penelitian selanjutnya benar-benar memahami system yang terdapat dalam pneumatic.

\section{DAFTAR RUJUKAN}

[1] C. A. Wijaya, J. Handhika, and S. Kartikawati, "Pengembangan Media Pembelajaran Pengendali Kecepatan Dan Soft Starting Motor Listrik Berbasis Arduino Pada Mata Kuliah Penggunaan Dan Pengaturan Motor," Jupiter (Jurnal Pendidik. Tek. Elektro), vol. 2, no. 2, p. 15, 2017, doi: 10.25273/jupiter.v2i2.1794.

[2] N. M. Dwijayani, "Development of circle learning media to improve student learning outcomes,” J. Phys. Conf. Ser., vol. 1321, no. 2, pp. 171-187, 2019, doi: 10.1088/17426596/1321/2/022099.

[3] P. Utami and P. Pardjono, "Perbedaan Jigsaw II dan GI terhadap pemahaman konsep dan pemecahan masalah masalah pada kompetensi mendiagnosis permasalahan pengoperasian PC dan Peripheral ditinjau dari motivasi belajar," J. Pendidik. Vokasi, vol. 3, no. 2, pp. 234-250, 2013, doi: 10.21831/jpv.v3i2.1604.

[4] Y. A. Prapaskah, E. Permata, and M. Fatkhurrokhman, "Trainer kit Pneumatik sebagai Media Pembelajaran pada Mata Kuliah Mekatronika Pendidikan diselenggarakan dengan cara melalui peran serta dalam penyelenggaraan dan Pendidikan yang baik ' $m$ edia ' berfungsi penyalur pembelajaran agar lebih efektif dan dalam," vol. 5, no. November, pp. 149-159, 2020. 
[5] G. P. Cikarge and P. Utami, "Analisis Dan Desain Media Pembelajaran Praktik Teknik Digital Sesuai Rps," Elinvo (Electronics, Informatics, Vocat. Educ., vol. 3, no. 1, pp. 92105, 2018, doi: 10.21831/elinvo.v3i1.20509.

[6] F. Eliza, "Trainer Sistem Kendali Elektronik Untuk Pembelajaran Mengoperasikan Sistem Kendali Elektronik," J. Edukasi Elektro, vol. 1, no. 2, pp. 110-118, 2017, doi: 10.21831/jee.v1i2.17414.

[7] M. Mashoedah, "Kajian Penggunaan Media Pembelajaran dalam Pelatihan Peningkatan Kompetensi Profesional Guru," Elinvo (Electronics, Informatics, Vocat. Educ., vol. 1, no. 1, pp. 17-25, 2015, doi: 10.21831/elinvo.v1i1.10875.

[8] H. Jati, D. Irmawati, P. Utami, B. Destiana, Sukirman, and D. Hariyanto, "Development of an online assessment based on the Shareable Content Object Reference Model (SCORM) to optimize the use of BeSmart UNY," J. Phys. Conf. Ser., vol. 1456, no. 1, 2020, doi: 10.1088/1742-6596/1456/1/012018.

[9] D. Darto, "Perencanaan Dan Simulasi Sistem Pneumatik Pada Mesin Pres Briket Blothong Berbantuan Perangkat Lunak," J. Teknol. dan Manaj. Inform., vol. 1, no. 1, 2015, doi: 10.26905/jtmi.v1i1.67.

[10] T. Nurseto, "Membuat Media Pembelajaran yang Menarik," J. Ekon. dan Pendidik., vol. 8, no. 1, pp. 19-35, 2012, doi: 10.21831/jep.v8i1.706.

[11] D. Imroni, "Rekayasa Rancang Bangun Sistem Pemindahan Material Otomatis Dengan Sistem Elektro-Pneumatik," J. Energi Dan Manufaktur, vol. 3, no. 1, 2012.

[12] N. Rohman, "Implementasi Media Pembelajaran Simulator Basic Pneumatic Pada Mata Kuliah Pneumatik Hidrolik,” J. Ilm. Pendidik. Tek. dan Kejuru., vol. 10, no. 1, pp. 1-5, 2017, doi: 10.20961/jiptek.v7i1.12646.

[13] B. Muqdamien, U. Umayah, J. Juhri, and D. P. Raraswaty, "Tahap Definisi Dalam Four-D Model Pada Penelitian Research \& Development (R\&D) Alat Peraga Edukasi Ular Tangga Untuk Meningkatkan Pengetahuan Sains Dan Matematika Anak Usia 5-6 Tahun," Intersections, vol. 6, no. 1, pp. 23-33, 2021, doi: 10.47200/intersections.v6i1.589.

[14] H. Wang et al., "Design and energy saving analysis of a novel isobaric compressed air storage device in pneumatic systems," J. Energy Storage, vol. 38, no. April, p. 102614, 2021, doi: 10.1016/j.est.2021.102614.

[15] M. G. Sofnivagi et al., "Rancang Bangun Sistem Elektro Pneumatik Untuk," vol. 4, no. 1, pp. 1-5, 2020.

[16] T. Bécsi, S. Aradi, Á. Szabó, and P. Gáspár, "Policy gradient based Reinforcement learning control design of an electro-pneumatic gearbox actuator," IFAC-PapersOnLine, vol. 51, no. 22, pp. 405-411, 2018, doi: 10.1016/j.ifacol.2018.11.577.

[17] C. Nie, Y. Shao, C. K. Mechefske, M. Cheng, and L. Wang, "Power distribution method for a parallel hydraulic-pneumatic hybrid system using a piecewise function," Energy, vol. 233, p. 121033, 2021, doi: 10.1016/j.energy.2021.121033. 